\title{
Desain Small Autonomous Passenger Ferry di Teluk Bintuni
}

\author{
Wahyu Rachmatdhani dan Wasis Dwi Aryawan \\ Departemen Teknik Perkapalan, Institut Teknologi Sepuluh Nopember (ITS) \\ e-mail:wasis@na.its.ac.id
}

\begin{abstract}
Abstrak-Teluk Bintuni terdapat Pelabuhan Babo dan pelabuhan khusus milik Tangguh LNG. Tangguh LNG sedang menambah pekerja yang ditujukan bagi orang asli Papua. Feri autonomous didesain untuk mengantarkan pekerja ini dari Pelabuhan Babo ke Tangguh LNG. Feri tidak mengharuskan adanya personil di atas kapal untuk beroperasi, tetapi ada operator yang mengawasi operasional kapal dari daratan (ground control station). Ini mengikuti acuan yang telah diberikan oleh Lloyd's Register (2016), AAWA (2016), DNVGL (2018), dan Maritime UK (2018). Pekerjaan studi ini mengikuti metodologi System Based Ship Design (SBSD) dikombinasikan dengan metode Risk Based Ship Design (RBSD). Untuk menerapkan kedua metode secara bersamaan, kedua metode ini sedikit disesuaikan agar sesuai dengan studi desain. Pre hazard analysis dilakukan untuk mengetahui keamanan kapal autonomous bila beroperasi, dari hasil analisis didapatkan sebanyak 67 hazardous event yang dapat terjadi. Diambil 9 penekanan untuk mendesain kapal ini yatu, mencegah penumpang menaiki atap feri, mencegah penumpang tergelincir di dermaga, mencegah agar kapal tidak dicuri, mencegah agar penumpang gelap tidak memasuki kapal, meminimalkan konsekuensi dalam kasus penumpang gelap, mencegah hilangnya kontrol navigasi selama operasi, meminimalkan konsekuensi jika kehilangan kontrol navigasi terjadi, mencegah kegagalan sistem emergency shutdown, dan mencegah kebakaran di atas kapal. Perlunya dipertimbangkan desain sistem dok untuk dapat bekerja secara autonomous yaitu dengan menggunakan vacuum mooring. Agar kapal dapat menghindari tubrukan secara autonomous terdapat penambahan sensor berupa kamera dan LIDAR untuk dapat menganalisis keadaan lingkungan sekitar. Desain akhir kapal didapatkan kapal dengan ukuran panjang $26 \mathrm{~m}$, lebar $6.5 \mathrm{~m}$, dan tinggi 3.8m yang ditenagai dengan battery dan digerakan dengan motor listrik.
\end{abstract}

Kata Kunci-Autonomous, Hazard, Feri, dan Desain.

\section{PENDAHULUAN}

$\mathrm{K}^{\mathrm{H}}$ ENDALI autopilot merupakan hal yang sangat lumrah di era teknologi dan komunikasi yang semakin berkembang ini. Tugas manusia semakin terbantu dengan hadirnya teknologi berupa robot. Teknologi ini sudah mulai masuk pada dunia transportasi yang salah satunya adalah kapal tanpa awak. Dengan adanya teknologi robot atau kendali otomatis pada kapal tanpa awak maka kapal tersebut diharapkan dapat membantu bahkan menggantikan tugas manusia dalam melakukanya tugasnya.

Tangguh mengadakan program pemagangan teknisi tangguh LNG yang merupakan sebuah program yang bertujuan untuk mempersiapan pesertanya adar dapat menjadi teknisi andal dan siap bekerja baik di BP maupun dalam proyek migas lain. Program ini ditujukan bagi orang asli Papua yang berdomisili di Papua Barat.

Untuk mendukung program tersebut akan dikembangkan berupa small autonomous passenger ferry yang berada di
Teluk Bintuni. Dengan adanya tiga dermaga yang dimanfaatkan untuk pelayanan penumpang umum yaitu Pelabuhan Bintuni, Babo, dan Pelabuhan khusus milik LNG Tangguh, kapal ini didesain untuk mengantarkan penumpang dari Pelabuhan Babo menuju Pelabuhan Khusus milik LNG Tangguh dengan jarak $44.5 \mathrm{Km}$.

\section{TINJAUAN PUSTAKA}

\section{A. Passenger Ship}

Konvensi IMO SOLAS mendifinisikan kapal pennumpang sebagai kapal yang membawa lebih dari 12 penumpang. Penumpang adalah semua orang di atas kpal selain anggota kru terlepas dari apakah mereka membayar biaya pelayaran atau tidak. Regulasi dan persyaratan classification society untuk desain kapal penumpang dan konstruksi tergantung pada ukuran kapal, jumlah penumpang, area operasi, dan jarak rute [1].

\section{B. Kapal Feri}

Peran Feri adalah transportasi yang rutin dan berkesinambungan untuk mengantar orang, bagasi, kendaraan, atau kereta api yang terkait. Ini adalah peran transportasi meskipun peluang hiburan dan belanja dapat menjadi bagian dari alat pemasaran. Muatan feri berkisar dari hanya penumpang sampai mengangkut penumpang, mobil, truk, jalur, dan kereta api. Feri berpergian di perairan terlindung, di laut terbuka, atau dalam kondisi ber-es [1].

\section{Autonomy}

Kata otonomi digunakan untuk menjelaskan kemerdekaan untuk negara dan masyarakat dan juga telah diadopsi untuk menjelaskan teknologi yang menghasilkan keputusan dan melakukan tugas tanpa interaksi manusia.

Merancang kendaraan otonom memperkenalkan parameter baru dan kendala dalam proses desain. Desain harus dapat bekerja dan merspons dengan benar dalam kerja bersamaan dengan benar dan dengan sistem otonom, itu harus cukup aman dan harus disetujui oleh regulasi [2].

Istilah Maritime Autonomous Surface Ships (MASS) telah diadopsi oleh Maritime Safety Comittee (MSC) dari International Maritime Organization (IMO) untuk latihan pelingkupan mereka yang diterima di MSC 98 pada 13 Juni 2017. Ringkasan Eksekutif pengajuan untuk latihan pelingkupan mengakuui bahwa penggunaan MASS menciptakan kebutuhan akan kerangka kerja peraturan untuk kapal-kapal semacam itu dan interaksinya serka koeksistensi dengan kapal-kapal berawak [3].

Beberapa organisasi pada saat ini sedang bekerja dalam mendefinisikan perbedaan tingkat autonomy. Kedua DNVGL dan Maritime UK telah menyatakan definisi autonomy dan tingkatan autonomy milik mereka. 


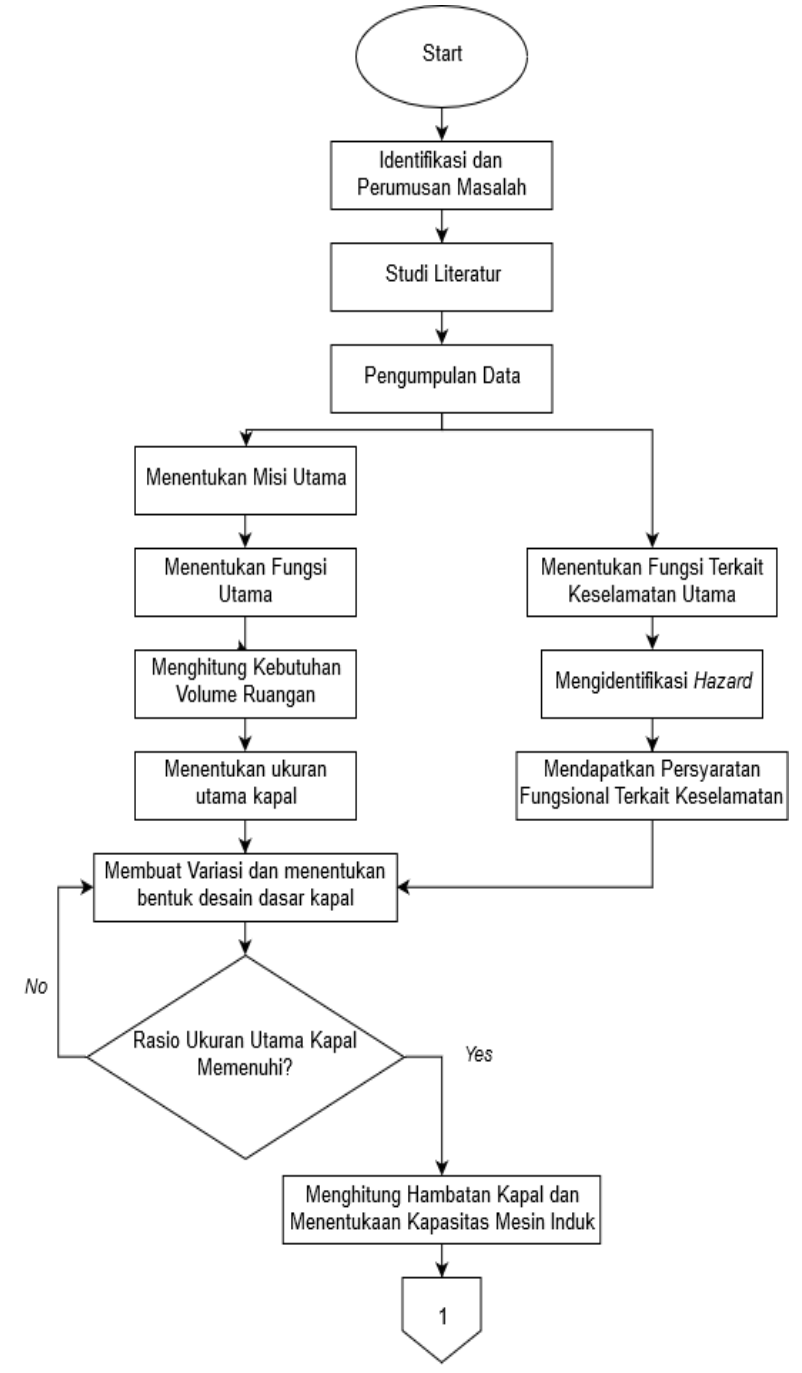

Gambar 1.. Diagram Alir Metodologi Penelitian

DNV-GL mengembangkan empat konsep yang dituliskan dalam guideline mereka. Guideline ini berisikan empat konsep yaitu [4]:

1. Decision Supported Navigational Watch, konsep ini didasarkan pada sistem pendukung keputusan yang ditingkan yang mendukung petugas di kapal yang bertanggung jawab atas pengawasan navigasi dalam melakukan tugas untuk fungsi navigasi.

2. Remote Navigational Watch, konsep ini didasarkan pada tugas, kewajiban, dan tanggung jawab petugas yang bertanggung jawab atas pengamatan navigasi yang dicakup oleh personel di pusat kendali jarak jauh di luar kapal.

3. Remote Engineering Watch Assisted by Personel on Board, konsep ini didasarkan pada tugas, tugas dan tanggung jawab seorang petugas yang bertanggung jawab atas pengawasan teknis yang ditanggung oleh personel di pusat kendali jarak jauh di luar kapal. Untuk Konsep ini, diasumsikan bahwa kru tersedia di kapal untuk melakukan tugas-tugas tertentu dan membantu personel jarak jauh sesuai kebutuhan.

4. Remote Engineering Watch, konsep ini didasarkan pada tugas, kewajiban, dan tanggung jawab seorang petugas yang bertanggung jawab atas pengawasan teknis yang ditanggung oleh personel di pusat kendali jarak jauh di luar kapal. Konsep ini mengasumsikan bahwa tidak ada kru yang tersedia di kapal untuk mendukung personel jarak jauh dalam melakukan fungsi rekayasa kelautan.

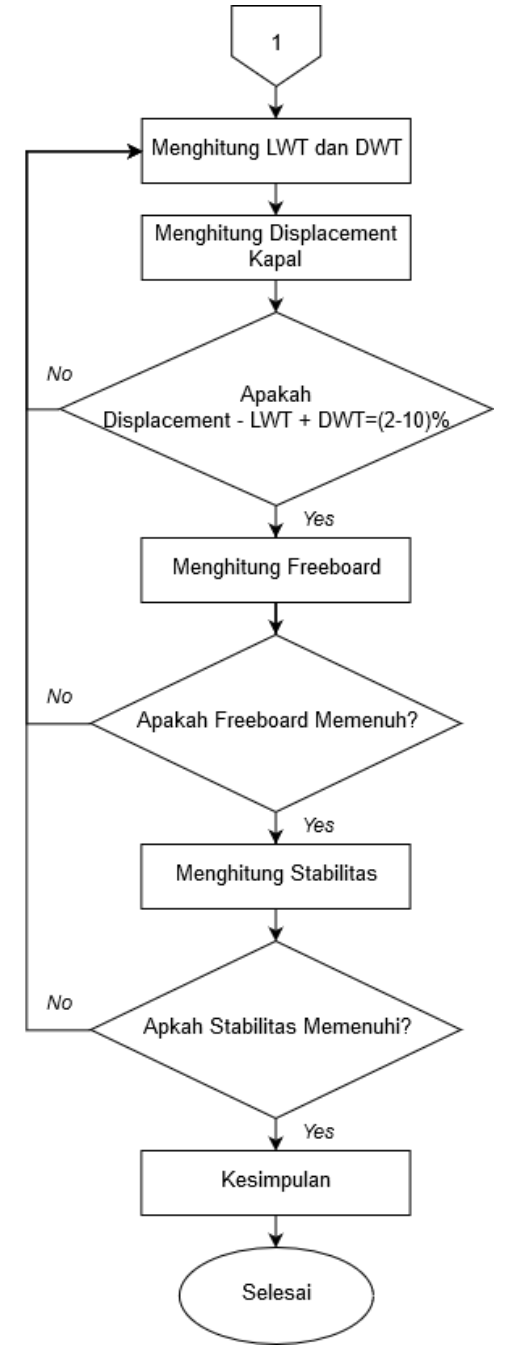

Gambar 2. Diagram Alir Metodologi Penelitian (Lanjutan)

Maritime UK mengatakan sejumlah sistem untuk mengkategorikan tingkat kontrol yang berlaku untuk kapal tanpa awak telah dikembangkan, Maritime UK sendiri pun mengkategorikan tingkatan autonomous dari nol sampai lima dengan penjalasan [3]:

o. Manned, kapal yang dikendalikan oleh operator di atas kapal.

1. Operated, di bawah kendali yang dioperasikan, semua fungsi kognitif dikendalikan oleh operator manusia.

2. Directed, di bawah kendali operator dengan beberapa tingkat penalaran dan kemampuan untuk merespons yang diimplementasikan ke dalam kapal tanpa awak. Mungkin merasakan lingkungan, melaporkan keadaanya dan menyarankan tindakan yang mungkin kepada operator, seperti meminta operator untuk memberikan informasi atau keputusan. Namun, wewenang untuk mengampil keputusan ada pada operator. Kapal tanpa awak akan bertindak hanyak jika diperintahkan dan / atau diizinkan untuk melakukanya.

3. Delegated, kapal tanpa awak sekarang berwenang untuk menjalankan beberapa fungsi. Menganalisis lingkungan, melaporkan keadaanya dan mendefinisikan tindakan dan melaporkan rencananya. Operator memiliki opsi untuk menolak rencana (veto) yang dinyatakan oleh kapal tanpa awak dan pengambilan keputusan dibagi antara operator dan kapal tanpa awak.

4. Monitored, kapal Tanpa awak akan menganalisis lingkungan dan melaporkan kondisinya. Kapal tanpa 


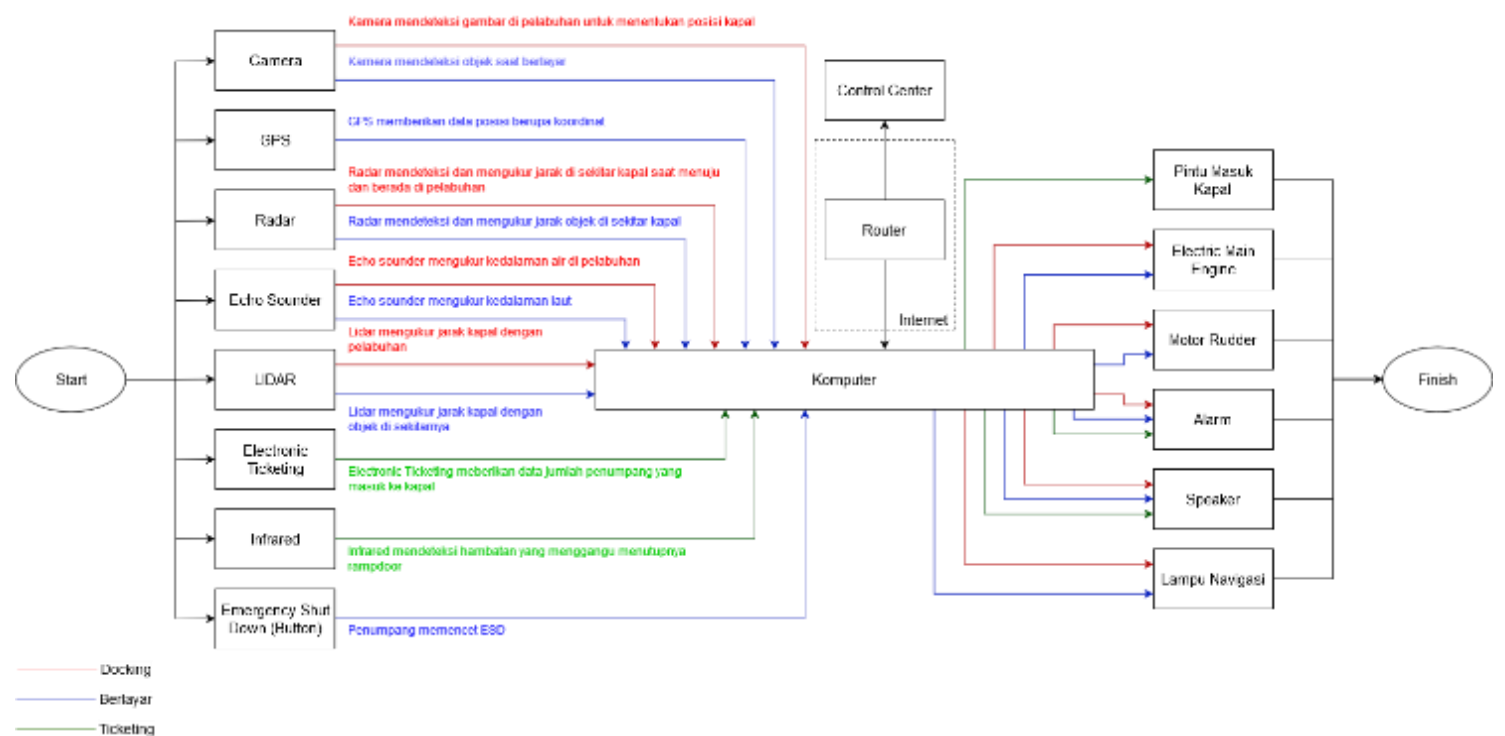

Gambar 2. Diagram Sistem Autonomos

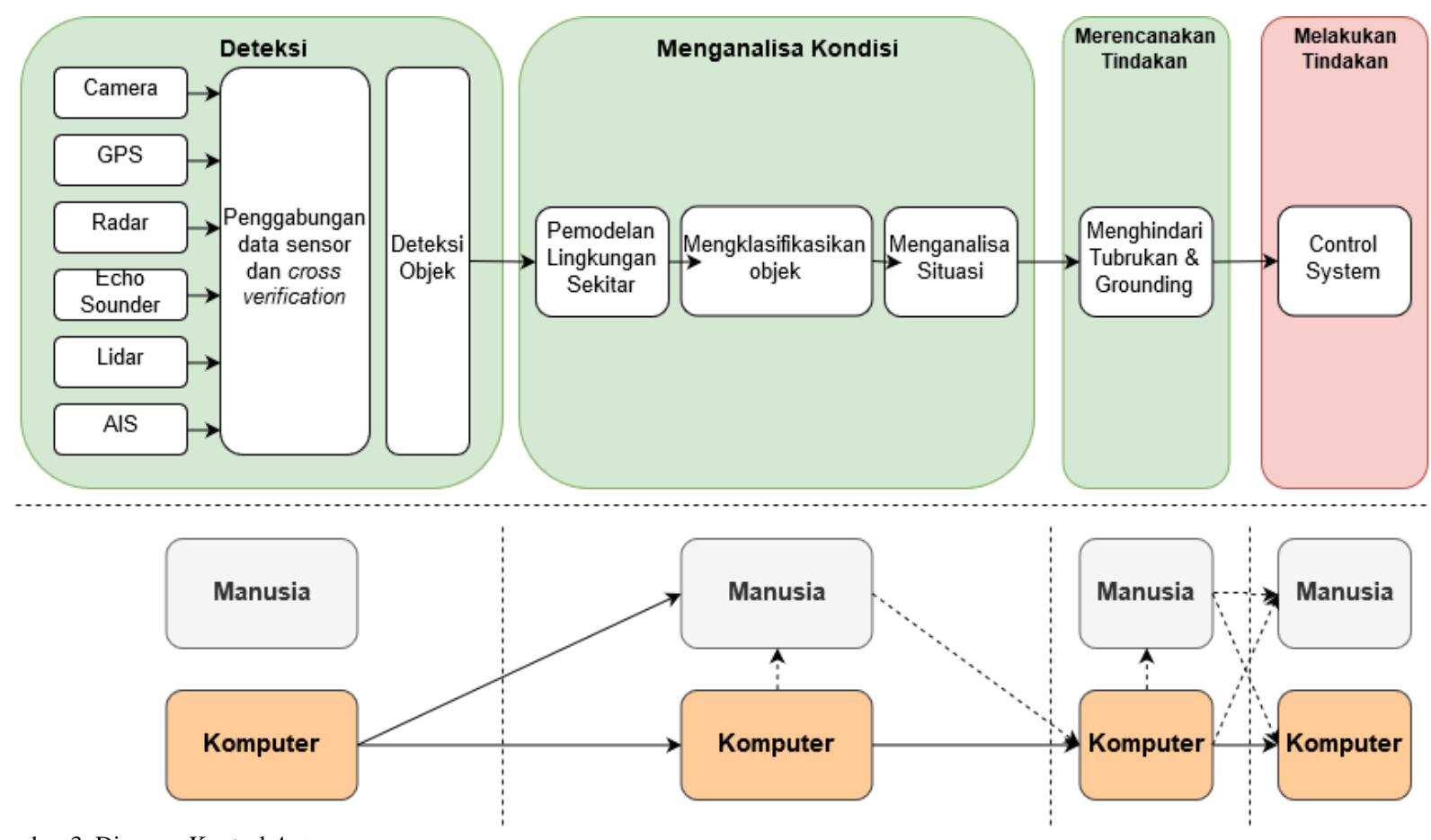

Gambar 3. Diagram Kontrol Autonomous

awak mendefinisikan tindakan, memutuskan, bertindak dan melaporkan tindakanya. Operator dapat memantau kejadian.

5. Autonomous, kapal tanpa awak akan menganalisis lingkungan, menentukan tindakan yang mungkin, memutuskan dan bertindak. Kapal tanpa awak diberikan tingkat maksimum kemandirian dan penentuan nasib sendiri dalam konteks kemampuan dan keterbatasan sistem. Fungsi Otonom dipanggil oleh sistem onboard pada kesempatan yang diputuskan sama, tanpa memberi tahu unit atau operator eksternal.

\section{Risk Assessment}

Penilaian risiko adalah keseluruhan proses melakukan analisis risiko dan evaluasi risiko. Analisis risiko adalah penggunaan informasi yang tersedia untuk mengidentifikasi bahaya dan memperkirakan risiko yang terkait dengan bahaya individu terkait dengan orang, lingkungan, dan properti. Ini bersifat proaktif karena berurusan dengan potensi kecelakaan dan bukan kecelakaan sebelumnya [5].

\section{METODOLOGI}

\section{A. Diagram Alir}

Secara umum, alur pengerjaan penelitian ini dapat dilihat pada Gambar 1.

\section{B. Analisis Autonomous}

Analisis autonomous digunakan untuk menentukan tingkatan autonomous yang akan digunakan, ini berfungsi untuk mengembangkan konsep desain awal kapal untuk berlanjut ke analisis teknis.

\section{Analisis Teknis}

Analisis teknis digunakan untuk menentukan beberapa hal yang meliputi, keselamatan, payload dan perhitungan aspek 


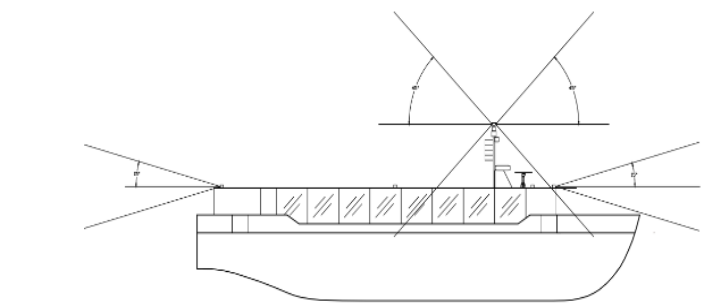

Gambar 4. Sudut Pandang Sensor Tampak Samping

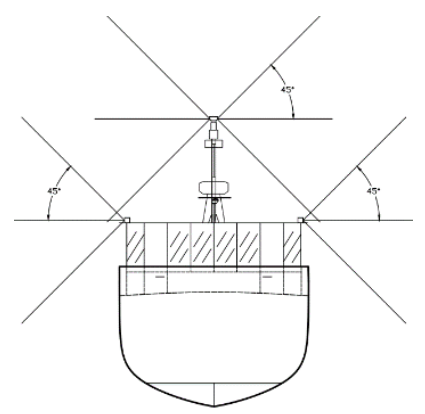

Gambar 5. Sudut Pandang Sensor Tampak Depan

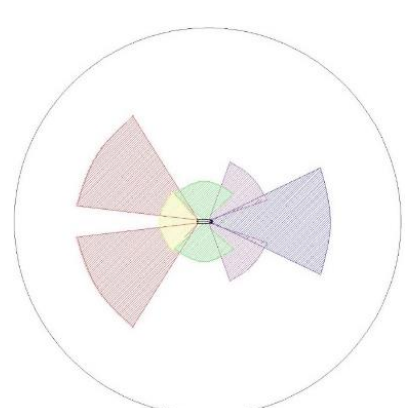

Gambar 6. Jarak Pandang Sensor Kamera dan LIDAR
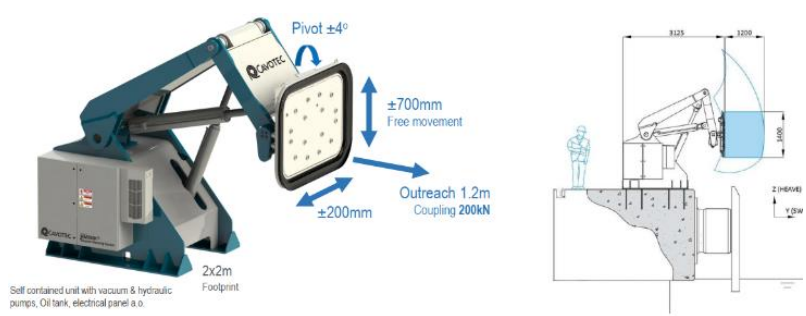

Gambar 7. MoorMaster 200K.

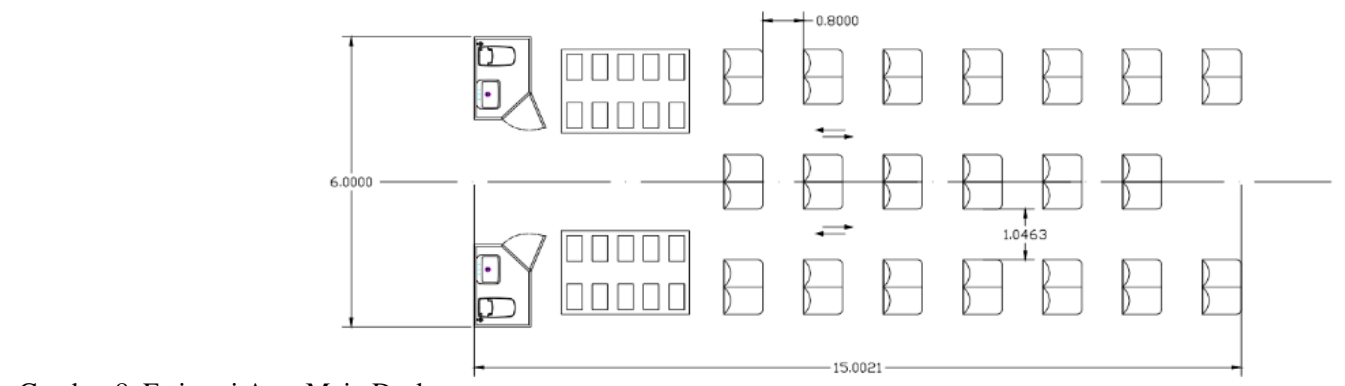

Gambar 8. Estimasi Area Main Deck

teknik umum kapal. Yang dimaksud dengan aspek teknik umum kapal meliputi perhitungan komponen LWT dan DWT, pemeriksaan displacement, pemeriksaan sarat, trim, dan stabilitas, pemeriksaan freeboard, pemeriksaan payload yang dibutuhkan, dan perhitungan hambatan dan propulsi kapal.

\section{KONSEP DESAIN SISTEM AUTONOMOUS}

\section{A. Tingkat Autonomous}

Teori tentang tingkatan autonomous didasarkan oleh tahun keluarnya code dan class guideline. Oleh karena itu Maritime Surfaace Ships UK Code of Practuice dan Class Guideline dari DNV-GL yang terbit pada tahun 2018 ini dipilih sebagai landasan tingkatan autonomous. Di sisi lain, Maritime Autonomous Surface Ships UK Code of Practice dikembangkan oleh beberapa organisasi dan salah satunya Rolls Royce yang sudah berhasil menguji kapal autonomous mereka.

Penulis memilih tingkatan autonomous, Remote Engineering Watch oleh DNV-GL dan Delegated oleh Maritime UK.

\section{B. Analisis Luas Penyeberangan Ketapang - Gilimanuk}

Gambar 2 merupakan diagram sistem autonomous. Sistem autonomous terdapat 3 jenis perangkat sensor, processor, dan aktuator.

Perangkat sensor yang berada di diagram sistem autonomous ini adalah kamera, GPS, radar, echo sounder, lidar, electronic ticketing, infrared, dan emergency shut down (button). Perangkat processor yang dibutuhkan oleh kapal autonomous ini adalah komputer yang berada di kapal dan komputer yang berada di control center. Aktuator menjalankan perintah dari processor ini adalah ramp door, electric main engine, motor rudder, alarm, speaker, dan lampu navigasi.

\section{Mode Operasional}

Pada dasarnya kontrol suatu fungsi dapat dibagi menjadi empat bagian utama yaitu:

\section{1) Detection}

Perolehan informasi yang relevan untuk pengendalian suatu fungsi. Informasi tersebut mungkin didasarkan pada sensor dan / atau persepsi manusia.

\section{2) Analysis}

Interpretasi informasi yang diperoleh ke dalam pemahaman situasional yang relevan untuk pengendalian fungsi.

\section{3) Planning}

Penentuan perubahan yang diperlukan dalam parameter kontrol untuk menjaga kinerja fungsi dalam frame yang berlaku.

4) Action

Mengefefktifkan perubahan yang direncanakan dari parameter kontrol, biasanya melalui aktuator yang dioperasikan melalui sistem kontrol. Gambar 3 menggambarkan bagaimana ini akan bekerja.

\section{Konsiderasi Autonomous}

Saat merancang kendaraan autonomous ada banyak faktor yang perlu dipertimbangkan. Kapal harus bisa berinteraksi dengan sistem autonomous, penumpang, dan lingkungan 
sekitarnya. Desain juga perlu mematuhi peraturan dan ketentuan sesuatu yang bisa menentang karena tidak ada peraturan khusus untuk autonomous.

Penempatan sensor seperti kamera dan LIDAR harus ditempatkan di tempat yang tidak terganggu sudut dan jarak pandangnya. Kamera milik Huawei memliki sudut pandang vertikal sebesar $-20^{\circ}$ sampai $90^{\circ}$ dan untuk LIDAR milik Opal memiliki sudut pandang vertikal sebesar $45^{\circ}$ Gambar 4, 5, dan 6 menunjukkan bagaimana sudut pandang sensor kamera dan lidar ini pada desain awal kapal.

Penentuan sistem mooring untuk kapal berlabuh harus ditentukan sebagai konsep desain awal ini. Hal yang paling memungkinkan untuk kapal dapat melakukan penambatan secara autonomous adalah menggunakan teknologi vacuum mooring yang digambarkan pada Gambar 7. Teknnologi ini memiliki kelebihan berupa:

1. Kapal ditambatkan dengan satu operator menggunakan remote control.

2. Kapal dapat diposisikan ulang tanpa perlu menghidupkan kapal dan tanpa pilot atau kapal tunda.

3. Sarat air dan variasi pasa surut dikelola secara otomatis tanpa keterlibatan manusia.

\section{ANALISIS TEKNIS}

\section{A. Pre Hazard Analysis}

Identifikasi bahaya dilakukan ddengan menggunakan metode PHA. Langkahnya adalah identifikasi hazards dan hazardous event, lalu mengidentifikasi penyebabnya dan konsekunsinya, langkah terakhir ialah menentukan tindakan mitigasi. Tiga kategori hazards dipertimbangkan: bahaya eksternal, bahaya fungsional, dan bahaya sistem. Beberapa referensi digunakan untuk membuat pre hazard analysis ini, yaitu class guideline DNV-GL, Advance Autonomous Waterborne Application (AAWA) paper, dan Mairitme UK practical code.

Didapatkan persyaratan fungsional terkait keselamatan yang dihasilkan dari pre hazard analysis yaitu:

1. Mencegah penumpang menaiki atap feri.

2. Mencegah penumpang tergelincir di dermaga.

3. Mencegah agar kapal tidak dicuri.

4. Mencegah agar penumpang gelap tidak masuk kapal.

5. Meminimalkan konsekuensi dalam kasus penumpang gelap.

6. Mencegah hilangnya kontrol navigasi selama operasi.

7. Meminimalkan konsekuensi jika kehilangan kontrol navigasi terjadi.

8. Mencegah kegagalan sistem emergency shutdown.

9. Mencegah kebakaran di atas kapal.

10. Meminimalkan konsekuensi dari kebakaran di kapal.

11. Mencegah kekurangan life jackets di kapal.

12. Mencegah kegagalan dalam pendaftaran penumpang yang memasuki feri

\section{B. Penentuan Ukuran Utama Kapal}

Pada awal menentukan ukuran utama kapal feri ini diperlukan estimasi area yang diperlukan di main deck. Untuk menentukan area di main deck penentuan payload yang berada di main deck diperlukan. Payload didapatkan dengan melakukan wawancara dengan pegawai tangguh LNG dan didapatkan yaitu: 40 penumpang, 40 koper, 40 tas, dan 40 kursi, toilet, ruang kontrol. Gambar 8 menunjukan hasil dari estimasi area main deck membutuhkan panjang sebesar $15 \mathrm{~m}$ dan lebar $6 \mathrm{~m}$.
Penentuan ukuran utama selanjutnya diperoleh dengan menggunakan ratio of main dimension unruk mendapatkan ukuran kapal sesungguhnya. Dari ratio of main dimensions ini didapatkan ukuran kapal dengan Lpp sepanjang 26m, lebar (B) $6.5 \mathrm{~m}$, tinggi (H) $3.8 \mathrm{~m}$, dan sarat (T) $1.8 \mathrm{~m}$.

\section{Analisis Hambatan}

Untuk menghitung hambatan kapal, digunakan metode Holtrop dan Mennen. Di dalam metode ini, Holtrop membagi hambatan total menjadi beberapa komponen hambatan. Dalam melakukan perhitungan hambatan utama kapal, ada ukuran urama yang harus terlebih dahulu diubah yaitu Lpp menjadi Lwl. Adapun rumus hambatan total adalah sebagai berikut [6]:

$\mathrm{R}_{\mathrm{T}}=\frac{1}{2} * \rho * \mathrm{~V}^{2} * \mathrm{~S}_{\mathrm{tot}} *\left(\mathrm{C}_{\mathrm{F}}(1+\mathrm{k})+\mathrm{C}_{\mathrm{A}}\right)+\frac{\mathrm{R}_{\mathrm{W}}}{\mathrm{W}} \mathrm{W}$

Didapatkan nilai hambatan total senilai $22.873 \mathrm{kN}$.

\section{Penentuan Motor Listrik, Baterai, dan Charger}

Untuk memilih motor listrik yang akan digunakan maka dicari motor listrik memenuhi perhitungan daya yang sebesar $201.131 \mathrm{~kW}$ untuk dapat mencapai kecepatan 16 knot. Perhitungan daya ini berakhir pada Shaft Horse Power (SHP) dikarenakan motor listrik yang akan dipakai memberikan spesifikasi pada SHP.

Motor Listrik yang dipilih adalah Torqeedo Deep Blue 100i 900 yang memiliki shaft power sebesar $100 \mathrm{~kW}$ dan setara dengan shaft power mesin outboard sebesaar 100.671 kW. Pada kapal ini menggunakan 2 motor listrik.

Untuk baterai dipilih dari baterai jenis lithium mengikuti rekomendasi dari motor Torqeedo yaitu menggunakan Deep Blue Battery (BMW i3 Series). Jumlah baterai yang dipakai motor listrik ini mengikuti saran yang diberikan oleh katalog yaitu dua unit baterai untuk satu motor listrik.

Baterai pun akan menyuplai keperluan listrik yang dibutuhkan kapal untuk dapat memfasilitasi penumpang dan menggunakan seluruh perlatan yang berada di atas kapal. Dengan perhitungan peralatan sebanyak 23 buah memerlukan daya sebesar $23.371 \mathrm{kWh}$ untuk satu kali perjalanan. Penulis memutuskan Deep Blue Battery (BMW I3 Series) akan digunakan dengan kapasitas sama seperti baterai yang digunakan untuk motor listrik yaitu 40kWh.

Charger $2900 \mathrm{~W}$ dengan charge current sebesar $50 \mathrm{~A}$ dipilih sebagai alat untuk mengecas baterai yang digunakan. Dengan baterai mempunyai voltase sebesar $360 \mathrm{v}$ dan kapasitas $40 \mathrm{kWh}$ dapat diketahui ampere hours nya sebesar 111.111 Ah. Lama waktu pengecasan baterai dapat diketahui dengan kapasitas baterai (Ah) dibagi dengan charge current. Didapatkan lama pengisian baterai selama 2.5 jam.

\section{E. Pengecekan Displacement}

Pengecekan dilakakuan pada saat kapal dengan muatan penuh dengan perhitungan hanya memperbolehkan perbedaan displacement dengan penjumlahan LWT dan DWT sebesar dua sampai sepuluh persen.
LWT $=\mathrm{W}_{\mathrm{ST}}+\mathrm{W}_{\mathrm{M}}+\mathrm{W}_{\mathrm{E \& O}}$
LWT $=141.174$ ton
DWT $=$ Payload $+\mathrm{W}_{\mathrm{C}}$
DWT $=13.417$ ton
$\Delta \quad=157.7$ ton
$\Delta_{\text {margin }}=3.109$ ton $=2 \%$ 


\section{F. Perhitungan Freeboard}

Lambung Timbul atau freeboard merupakan daya apung cadangan kapal dan memiliki dampak terhadap keselamatan kapal, naik kesalamatan kru kapal, atau penumpang kapal, dan kapal itu sendiri. Pemeriksaan freeboad untuk untuk kapal kecil harus memenuhi kriteria yang telah disyaratkan oleh Kementrian Perhubungan Republik Indonesia. Kriteria tersebut disebutkan dalam Standar Kapal Non-Konvensi Berbendera Indonesia Bab VI di mana freeboard minimum tidak boleh kurang dari $250 \mathrm{~mm}$ [7].

Freeboard $=\mathrm{H}-\mathrm{T}$

$$
=3.8 \mathrm{~m}-1,8 \mathrm{~m}=2 \mathrm{~m}
$$

\section{G. Perhitungan Stabilitas}

Pengecekan stabilitas dilakukan untuk mengetahu stabilitas kapal dan untuk memenuhi standard keselamatan pelayarasn SOLAS dan IMO. Perhitungan stabilitas ini dilakukan dengan mengecek lima loadcase dengan variasi tangki penuh, terisi $50 \%$, dan $10 \%$ yaitu:

1. Kapal kondisi dipenuhi 40 orang dan tangki terisi.

2. Kapal kondisi dipenuhi 40 orang, 40 koper, dan tangki terisi.

3. Kapal kondisi dipenuhi 40 orang, 40 tas, dan tangki terisi.

4. Kapal kondisi dipenuhi 40 orang, 40 koper, 40 tas, dan tangki terisi.

5. Kapal tidak terdapat penumpang dan tangki terisi

Dengan kondisi trim pada masing-masing loadcase sebesar:

1. Loadcase $1=-0.484 \mathrm{~m}$ (trim by stern)

2. Loadcase $2=-0.478 \mathrm{~m}$ (trim by stern)

3. Loadcase $3=-0.483 \mathrm{~m}$ (trim by stern)

4. Loadcase $4=-0.477 \mathrm{~m}$ (trim by stern)

5. Loadcase $5=-0.578 \mathrm{~m}$ (trim by stern)

Didapatkan hasil analisis stabilitas untuk masing masing loadcase:

1. Loadcase $1=$ Pass

2. Loadcase 2 = Pass

3. Loadcase $3=$ Pass

4. Loadcase $4=$ Pass

5. Loadcase $5=$ Pass

\section{KESIMPULAN}

1. Teori yang digunakan untuk mendesain kapal ini mengacu pada badan klasifikasi Lloyd's Register dan DNV GL.

2. Teori yang digunakan selain badan klasifikasi berasal dari Maritime UK yang mengeluarkan MASS Code of
Practice dan Paper milik AAWA yang dipimpin oleh Rolls Royce.

3. Kapal akan dijalankan secara autonomous dan remote oleh satu operator di ground control station.

4. Sistem autonomous dibedakan antara pelayaran, mooring system, dan ticketing.

5. Metode desain yang sesuai untuk digunakan adalah System Based Ship Design (SBSD) yang digabungkan dengan Risk Based Ship Design (RBSD).

6. Kapal didesain untuk mengangkut penumpang sebanyak empat puluh orang dengan barang bawaan berupa koper dan tas untuk masing-masing penumpang.

7. Penggunaan e-ticketing dengan flap gate barrier diletakan pada buritan kapal.

8. Peletakan Control Room berada di buritan kapal.

9. Peletakan kursi penumpang dibuat 3 baris agar mempunyai ruang gerak yang luas.

10. Kapal berlabuh dengan sisi kapal menghadap pelabuhan dan menggunakan vacuum mooring untuk mooring system.

11. Kapal menggunakan penggerak motor listrik.

12. Kapal menggunakan baterai sebanyak lima buah.

13. Kapal menggunakan charger sebanyak lima buah.

14. Penempatan sensor berupa kamera dan LIDAR berada di atap passenger room.

15. Kapal memiliki 67 hazardous event dan terdapat 12 poin yang perlu diertimbangkan.

16. Pengecekan displacement mempunyai perbedaan sebesar $2 \%$.

17. Kapal dinyatakan lolos kriteria stabilitas dengan menganalisis 5 kondisi yang dijalankan pada software maxsurf stability.

\section{DAFTAR PUSTAKA}

[1] T. Lamb and Society of Naval Architects and Marine Engineers, Ship Design and Construction. Jersey City, New Jersey: Society of Naval Architects and Marine Engineers, 2003.

[2] G. Havdal, C. T. Heggelund, and C. H. Larssen, "Design of a Small Autonomous Passenger Ferry," Norwegian University of Science and Technology, 2017.

[3] Maritime UK, Being a Resposible Industry: Maritime Surface Ships UK Code of Practice - A Voluntary Code. Society of Maritime Industries, 2018.

[4] B. J. Vartdal and A. Jørgensen, "Autonomous and remotely operated ships - status and outlook." DNV GL AS, 2018.

[5] M. Rausand, Risk Assessment: Theory, Methods, and Applications. Hoboken, New Jersey: Wiley, 2013.

[6] E. V Lewis, Principle of Naval Architecture, Vol. II, 2nd ed. Jersey: SNAME, 1988.

[7] K. Abrar, "Kajian Teknis dan Ekonomis Desain Konversi Kapal Penyebrangan Wisata Dengan Konsep Solar-Powered Boat di Kawasan Mandeh Sumatera Barat," Institut Teknologi Sepuluh Nopember Surabaya, 2019. 